This item was submitted to Loughborough's Research Repository by the author.

Items in Figshare are protected by copyright, with all rights reserved, unless otherwise indicated.

\title{
Novel mechatronic solutions incorporating inerters for railway vehicle vertical secondary suspensions
}

\section{PLEASE CITE THE PUBLISHED VERSION}

https://doi.org/10.1080/00423114.2014.983529

\section{PUBLISHER}

(c) Taylor \& Francis

\section{VERSION}

AM (Accepted Manuscript)

\section{PUBLISHER STATEMENT}

This work is made available according to the conditions of the Creative Commons Attribution-NonCommercialNoDerivatives 4.0 International (CC BY-NC-ND 4.0) licence. Full details of this licence are available at: https://creativecommons.org/licenses/by-nc-nd/4.0/

\section{LICENCE}

CC BY-NC-ND 4.0

\section{REPOSITORY RECORD}

Matamoros-Sanchez, Alejandra Z., and Roger Goodall. 2014. "Novel Mechatronic Solutions Incorporating Inerters for Railway Vehicle Vertical Secondary Suspensions". Loughborough University. https://hdl.handle.net/2134/27064. 


\title{
RESEARCH ARTICLE
}

\section{Novel mechatronic solutions incorporating inerters for railway vehicle vertical secondary suspensions}

\author{
Alejandra Z. Matamoros-Sanchez ${ }^{\mathrm{a}}$, Roger M. Goodall ${ }^{\mathrm{b}}$ \\ ${ }^{a}$ Engineering Faculty, Universidad de Los Andes, Merida 5101, Venezuela; \\ ${ }^{\mathrm{b}}$ Department of Electronic, Electrical and Systems Engineering, Loughborough University, \\ Loughborough, LE11 3TU, UK
}

(v3.5 released June 2008)

\begin{abstract}
This paper discusses the effects of inerter-based passive networks in the design of novel mechatronic solutions for improving the vertical performance of a bogied railway vehicle. Combinations of inerter-based structures and active suspensions comprise distinct novel mechatronic solutions for the vertical secondary suspension of the vehicle. The parameters of the active and passive parts of the overall configuration are optimised so that a synergy arises to enhance the vehicle vertical performance and simplify common mechatronic suspension design conflicts. The study is performed by combining inerter-based suspensions with well established active control (output-based and model-based) strategies for ride quality enhancement. Also, a novel nonlinear control strategy, here called 'Adaptive Stiffness', is incorporated for suspension deflection regulation to complement the well known local implementation of skyhook damping. This would complete a significant set of control strategies to produce general conclusions. The vehicle performance is assessed through the vertical accelerations of the vehicle body as an initial investigation. Attained results show the potential of the inerter concept for innovating mechatronic technologies to achieve substantial improvements in railway vehicle vertical ride quality with reduced actuator force.
\end{abstract}

Keywords: inerter; passive suspension; active suspension; railway vehicle; mechanical control; hybrid suspension

\section{Introduction}

The classification of vehicle suspensions -and vehicle dynamics control in the same context- involves a number of different criteria. Some suspension solutions do not need external power supplies, such as passive and semi-active (the former having fixed characteristics as opposed to the latter for which the characteristic can be rapidly varied by electronic controllers), whereas others do need an external power supply, known as active or full-active (see [1]). Therefore, according to the control law designed for the full-active suspensions, energy can flow in or out of the dynamic system. Suspension systems in the secondary layer are studied in this paper with particular focus on the design of hybrid -novel mechatronic passive-plus-activesuspensions for vertical ride quality enhancement.

Fijalkowski discussed in [2] about hybrid suspensions in automotive, and Smith et al. in [2] on optimisation for vibrating structures. The common and main objective of combined suspensions is to reduce power demands and actuator size in terms

\footnotetext{
*Corresponding author. Email: matamoros@ula.ve

(p)//wwwinfor 
of maximum forces requirements (see, for example, Corriga et al. [3] and Guia et al. [4]). Some work has been done in this direction for suspension systems in general, by supplementing the actuators with simple arrangements of springs and dampers, or even redesigning the system parameters to constitute the passive part of the suspension as in [2]. In general however, reduced actuator size also results in reduced power demands and energy consumption, but practically these are small in terms of total power/energy requirements for a railway vehicle. In addition, fitting an actuator into a suspension is often practically tricky, and so this paper's focus is upon reducing actuator force and size.

Moreover, for railway suspensions, most of the applications of mechatronic suspensions have been investigated to work together with the conventional passive suspensions $[5,6]$. These may be further aided by springs in the modification of the actuator bandwidth, for example, when considering real actuator dynamics [7]. However, no attempt to create cooperation between inerter-based suspensions and active suspensions has been found in the literature. The only previous work on developing mechatronic solutions using the inerter concept are the mechatronic network systems proposed by Wang and Chan for the synthesis of high-order and switching impedances [8-11].

After the introduction of the inerter by Smith in 2002 [12], a number of research studies have demonstrated enhancement in vehicle dynamics through the use of mechanical passive control complemented by the inerter concept $[13,14]$. The inerter was conceived as a two-terminal mechanical element characterised for developing a linear force which is proportional to the relative acceleration across the terminals. The invention has led to passive control accomplishment through novel - inerter-based - mechanical devices [15-19], with success implementation in racing cars [20]. In particular for railway vehicles, the use of inerter-based passive networks has proven benefits for ride quality and stability enhancement [21-26]. Nevertheless these mechanical networks define, from the control viewpoint, a compensator structure which is still limited compared with the control laws that are realisable via active suspensions.

Mechatronic solutions are emerging as one of the important sources of innovation for future generations of railway vehicles [27], and a worldwide operational example of using mechatronics is the tilting train. There has been also a growing consensus about the future use of active control to improve railway vehicles' running behaviour through new technologies in the primary suspensions. However, different proposed solutions are still in the experimental stage. Progress on concepts for mechatronic secondary suspensions is likewise well advanced, although the benefits attained so far are yet unconvincing for the railway industry [27]. Therefore, research interests continue.

As a contribution to the field of railway vehicle secondary suspension development, this study is supported by the following facts, together with the novelty of the inerter concept for passive mechanical control:

(1) It is still necessary to find a solution whose benefits justify the investments in the involved technology,

(2) The vertical dynamic is a relatively simple case of study in railway vehicles for a first investigation on the potential of the inerter within integrated technologies.

(3) Passive suspensions consisting of springs, dampers and inerters could selectively compensate for resonant frequencies of the sprung mass dynamics, as opposite to spring-damper conventional suspensions. This may reduce active force requirements in active suspensions. 


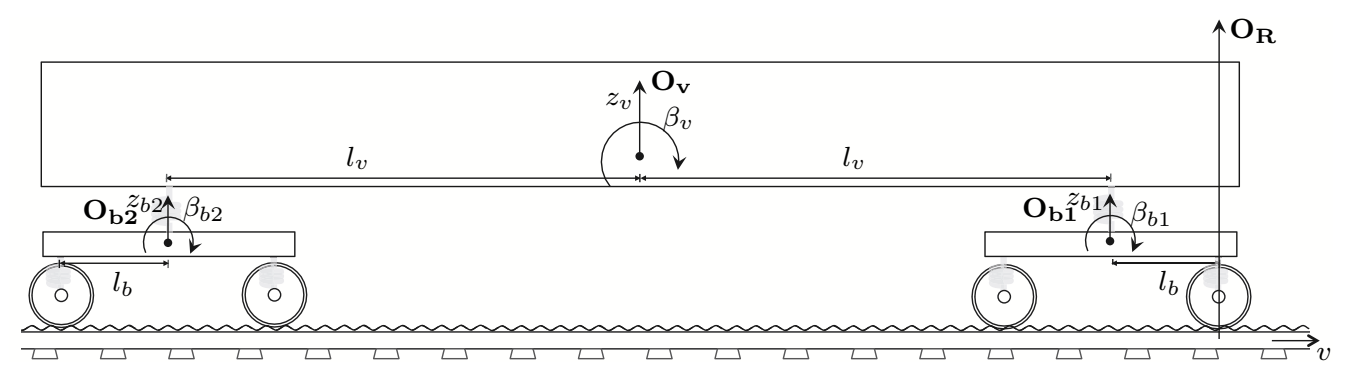

Figure 1. Side-view multibody representation of a railway vehicle with detail on the local coordinates and bodies DoF.

In particular, this scientific paper addresses the analysis and design of ideal hybrid suspensions consisting of conventional mechatronic systems - active controlaugmented by inerter-based devices - passive control. The idea here is to accomplish cooperative control in the vehicle secondary suspension for enhancing vertical ride quality with optimal actuator force requirements. Simplified theoretical models of the vehicle are used to reveal the principal benefits arising from the inerter concept.

\section{Mathematical model of a railway vehicle with conventional suspensions}

As this work concerns the vertical ride quality, mathematical modelling of the vertical and pitch modes of the bogied railway vehicle for decentralised control design is considered. The model describes the dynamics of a single vehicle. Detailed geometry of the vehicle bodies, aerodynamic factors, body flexibilities, non-linearities of the wheel/rail interaction forces, are some of the engineering aspects not accounted for in the model. Moreover, for assessment of bounce and pitch modes only, the model constrains the lateral, yaw and roll motions of the vehicle given the significant decoupling with the corresponding modes. The longitudinal dynamic is assumed stationary at a nominal travelling speed. This turns the representation into a planar model of the bogied — two-suspension layer - vehicle.

Thus, the model used throughout this paper is a linear incremental model with respect to the vehicle's equilibrium condition fixed to the local coordinates origin $\mathbf{O}_{\mathbf{v}}, \mathbf{O}_{\mathrm{b} 1}$, and $\mathbf{O}_{\mathrm{b} 2}$ from Figure 1. It is written in the Laplace transformed domain as

$$
\begin{aligned}
s^{2} m_{v} \hat{z}_{v} & =\hat{F}_{a 1}+\hat{F}_{a 2}+\hat{F}_{u 1}+\hat{F}_{u 2} \\
s^{2} I_{v y} \hat{\beta}_{v} & =l_{v}\left(\hat{F}_{a 1}-\hat{F}_{a 2}+\hat{F}_{u 1}-\hat{F}_{u 2}\right) \\
s^{2} m_{b} \hat{z}_{b, i} & =-\hat{F}_{a, i}-\hat{F}_{u, i}+\hat{F}_{p, i,(2 i-1)}+\hat{F}_{p, i, 2 i} \\
s^{2} I_{b y} \hat{\beta}_{b, i} & =l_{b}\left(\hat{F}_{p, i,(2 i-1)}-\hat{F}_{p, i, 2 i}\right)
\end{aligned}
$$

where the symbol ^ denotes Laplace transform, $F_{p, i, j}$ and $F_{a, i}$ are, respectively, the forces applied by the conventional primary and secondary suspension, and $F_{u, i}$ the control forces applied by the novel mechatronic secondary suspension. The freebody diagram of the vehicle body and the bogies are supplied in Figure 2, and geometrical, mass and inertia parameter specifications are contained in Table 1. 


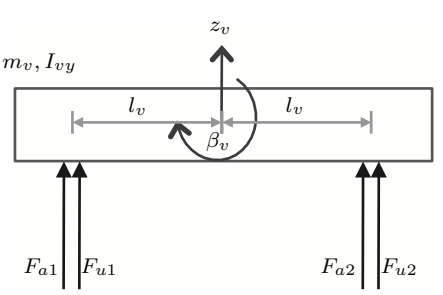

(a) Free-body diagram for the vehicle body.

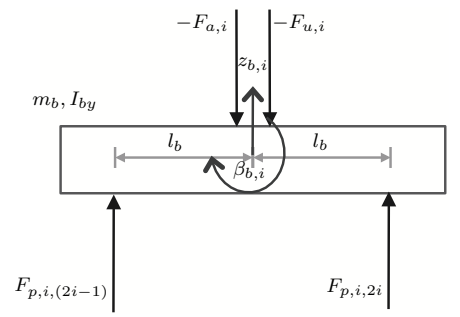

(b) Free-body diagram for the $i$-th vehicle bogie.

Figure 2. Free-body diagrams for the vehicle main bodies.

Table 1. Parameter values for the Side-View model (adapted from [5] for high damping airsprings [28].)

\begin{tabular}{clr}
\hline Sym. & Parameter & Value \\
\hline$m_{v}$ & Vehicle body mass $[\mathrm{kg}]$ & $38 \times 10^{3}$ \\
$m_{b}$ & Bogie mass [kg] & $2.5 \times 10^{3}$ \\
$I_{v y}$ & Vehicle pitch inertia $\left[\mathrm{kgm}^{2}\right]$ & $2.31 \times 10^{6}$ \\
$I_{b y}$ & Bogie pitch inertia [kgm $\left.{ }^{2}\right]$ & $2 \times 10^{3}$ \\
$l_{v}$ & Semi-longitudinal spacing of secondary suspension $[\mathrm{m}]$ & 9.5 \\
$l_{b}$ & Semi-longitudinal spacing of wheelsets [m] & 1.25 \\
$k_{a}$ & Change of area stiffness $(\times 2)\left[\mathrm{Nm}^{-1}\right]$ & $3.13 \times 10^{5}$ \\
$k_{s}$ & Airspring stiffness $(\times 2)\left[\mathrm{Nm}^{-1}\right]$ & $1.24 \times 10^{6}$ \\
$k_{r}$ & Reservoir stiffness $(\times 2)\left[\mathrm{Nm}^{-1}\right]$ & $4.88 \times 10^{5}$ \\
$c_{r}$ & Airspring damping $(\times 2)\left[\mathrm{Nsm}^{-1}\right]$ & $1 \times 10^{5}$ \\
$k_{p}$ & Primary suspension stiffness $(\times 2)\left[\mathrm{Nm}^{-1}\right]$ & $5 \times 10^{6}$ \\
$c_{p}$ & Primary suspension damping $(\times 2)\left[\mathrm{Nsm}^{-1}\right]$ & $3.58 \times 10^{4}$ \\
$v$ & Vehicle speed [ms $\left.{ }^{-1}\right]$ & 55 \\
\hline
\end{tabular}

Symmetry about the longitudinal axis is considered for the planar model. Thus, side suspensions are concentrated in a planar suspension model by duplicating $(\times 2)$ the suspension parameters.

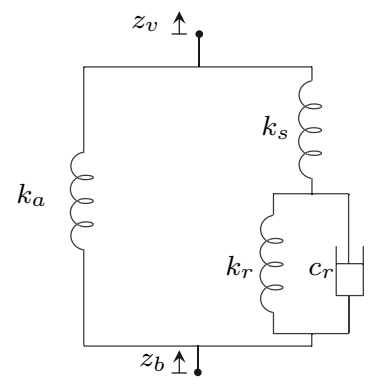

Figure 3. Nishimura model for the conventional secondary suspension.

\subsection{Conventional suspension models}

Two stages of suspension compose a typical railway vehicle, as already shown in Figure 1. Conventionally, these comprise stiff springs and dampers in the primary suspension stage, and airsprings in the secondary. Whilst the primary suspension model is fairly simple, the model for the airsprings in the secondary suspension is more complicated due to the frequency-dependent behaviour they exhibit. In fact, there is still not consensus on the most appropriate airspring model; as a reference, Bruni et al. offer a review on some existing models in [29]. This paper considers the one-dimensional models of the primary and secondary suspensions from [21], where the Nishimura model is used (Figure 3). We make assumptions of high damping coefficient for the airsprings. Hence, internal resonances due to the fluid inertance of the accelerated air in the air bag-reservoir interchange phase are negligible, justifying the appropriateness of the chosen model [28]. Thus, for 
the railway vehicle in Figure 1 the force applied by the $j$-th primary suspension is given by

$$
\hat{F}_{p, i, j}=\mathrm{Y}_{p}(s) s\left(\hat{z}_{w, j}-\left(\hat{z}_{b, i}+(-1)^{j-1} l_{b} \hat{\beta}_{b, i}\right)\right)
$$

where $j=1,2(j=3,4)$ is restricted to $i=1(i=2)$ and identifies, respectively, the front and rear suspensions and track inputs of the leading (trailing) bogie. Similarly, the $i$-th airspring force is given by

$$
\hat{F}_{a, i}=\mathrm{Y}_{a}(s) s\left(\hat{z}_{b, i}-\left(\hat{z}_{v}+(-1)^{i-1} l_{v} \hat{\beta}_{v}\right)\right)
$$

where $i=1$ and $i=2$ identify, respectively, the front and rear airsprings and bogies. For this, the admittance functions of the primary and secondary suspensions are written as:

$$
\begin{aligned}
\mathrm{Y}_{p}(s) & =\left(k_{p} s^{-1}+c_{p}\right) \\
\mathrm{Y}_{a}(s) & =\frac{s \gamma_{c}+\gamma_{k}}{s(s+\alpha)}
\end{aligned}
$$

with: $\gamma_{c}=k_{s}+k_{a}, \gamma_{k}=\frac{k_{s}\left(k_{r}+k_{a}\right)+k_{r} k_{a}}{c_{r}}$, and $\alpha=\frac{k_{s}+k_{r}}{c_{r}}$. The description and value of the conventional vehicle side-view model parameters are listed in Table 1.

\section{2. $\quad$ Track models for suspension design}

The moving irregularity model from [21] representing a nominal track is used here for assessment of the vertical ride quality. In [21], the irregularity rate $\dot{\delta}_{z}$ is described as a white random stationary process with a Gaussian distribution which is dependent on the vehicle's travelling speed. Even though the 'infinite' connotation results slightly unrealistic for a real track, this simplification is yet valid and useful for suspension design purposes (see for example [5] for a comparison with realistic data and a fourth order spatial power spectrum best fit model). Hence, the p.s.d. of the track elevation rate in the time frequency, $\dot{S}_{t} \dot{\delta}_{z}\left(\omega_{t}\right)$, for a speed $v$ and vertical roughness coefficient $\Omega_{z}$, can be written as

$$
\dot{S}_{t}^{\dot{\delta}_{z}}\left(\omega_{t}\right)=2 \pi \Omega_{z} v \quad\left[(\mathrm{~m} / \mathrm{s})^{2}(\mathrm{rad} / \mathrm{s})^{-1}\right]
$$

$\left(\Omega_{z}=2.5 \times 10^{-7}[\mathrm{~m}]\right.$ is a typical value for a good quality track $[5,30-32]$ and is used throughout this paper). Nevertheless, to prevent unrealistic numerical results because of the flat spectrum of $\dot{S}_{t}^{\dot{\delta}_{z}}\left(\omega_{t}\right)$, a first order low-pass filter with corner frequency of $20[\mathrm{~Hz}]$ of the track input in Equation 5 is introduced.

In active suspension design, special attention should be given to the suspension deflection due to clearance limitations and to the maximum active forces acceptable for the actuator. If this deterministic requirement is not accounted for, unrealistic active suspension strategies may arise, especially those based upon the skyhook damping concept [33]. A typical deterministic profile producing worst case conditions for those physically constrained variables is a railway gradient $f_{w z}(t)$ with a superimposed acceleration limit in the transition of $0.4\left[\mathrm{~ms}^{-2}\right]$ (i.e. of approximately $4[\% \mathrm{~g}]$ ) for a nominal speed of $55\left[\mathrm{~ms}^{-1}\right]$, resulting in a transitional section of 
$1[s][5,34]$. Thus,

$$
\dot{f}_{w z}(t)=0.4 \int_{-\infty}^{t}\left(1\left(\tau_{1}-t_{0}\right)-1\left(\tau_{1}-\left(t_{0}-1\right)\right)\right) d \tau_{1}\left[\mathrm{~ms}^{-1}\right]
$$

\section{Objectives and challenges in mechatronic suspension design}

The ultimate objective for the vertical secondary suspensions of a railway vehicle is the enhancement of passengers' ride experience, besides providing adequate support to the vehicle cabin. Ride characteristics are assessed in this paper by computation of the vehicle body root-mean-square (r.m.s.) leading, middle and trailing accelerations $\underline{y_{\ddot{z} v}}$ :

$$
\underline{y_{\ddot{z} v}}=\left[\begin{array}{llll}
\ddot{z}_{v}+l_{v} \ddot{\beta}_{v} & \ddot{z}_{v} & \ddot{z}_{v}-l_{v} \ddot{\beta}_{v}
\end{array}\right]^{T}\left[\mathrm{~ms}^{-2}\right]
$$

These are adopted as ride quality penalisation indices reunited in the vector $\underline{J_{1}}$, presented in percentage of gravity units:

$$
\underline{J_{1}}=\left[\begin{array}{lll}
J_{1 L} & J_{1 M} & J_{1 T}
\end{array}\right]^{T}[\% g]
$$

where the sub-indices $L, M, T$ stand for leading, middle and trailing positions, respectively. For this, considerations of a straight track and constant running speed are made $[5,6,31,32]$. Unweighted accelerations were decided for this study, following recent research showing that the standard norms typically used to determine ride comfort indices (e.g. ISO 2631 [35], the Sperling's method [36], or ENV 12299 [37]) underestimate the effects of vibrations on the passengers' normally sedentary activity (e.g. writing, reading, sketching, working with laptops) [38-40]. This consideration would avoid hiding the effects of the inerter on the mechatronic structures and the vehicle performance. Future studies will adopt the standard norms to set further conclusions on the potential of the proposed synergy.

In the design of railway vehicle suspensions for ride quality enhancement, improving the measurement at the most unfavourable location on the vehicle body is a common sense practice followed here. This is achieved by minimising the least ride quality penalisation index, ${\underline{J_{1}}}^{\text {sup }}$, calculated for the vehicle response to the track irregularities described in Equation 5. For the case of incorporating mechatronic suspensions with linear dynamical characteristics only, $J_{1}$ is obtained as the

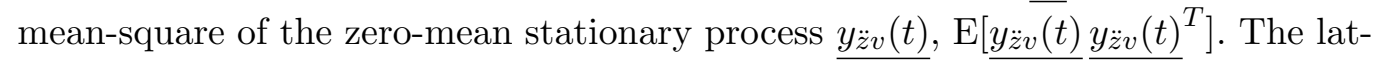
ter, which is also equivalent to the autocorrelation function of $y_{\ddot{z} v}(t)$, is calculated by using the state-space method based on the solution of the Lyapunov stability equation for the stationary process. An alternative to this, was to use the spectral density $S_{t}^{y_{z v}}(\omega)$ from frequency-based analysis. Differently, for the vehicle with a nonlinear control strategy in the mechatronic suspension, calculation of $J_{1}$ relies only on the r.m.s. value of the output data obtained from simulations.

Further, some physical constraints conflict with the achievement of high levels of ride quality. In particular, special attention is given here to the trade-off between ride quality, secondary suspension deflection, and active force magnitude. The referred characteristics are assessed in the suspension deflection and active force indices, $J_{2}$ and $J_{3}$, respectively. Also, mean power consumption could be easily as- 
sessed for an idealised actuator using $\mathcal{P}=\mathrm{E}\left[F_{c}\left(\dot{z}_{2}-\dot{z}_{1}\right)\right]$ for the stochastic mean power as in [28], and $\mathcal{P}=F_{c}\left(\dot{z}_{2}-\dot{z}_{1}\right)$ for consumption due to deterministic track features. However, the true power and thus energy consumption will be affected significantly by the choice of actuator technology, and in practice energy consumption for an active suspension has been shown to be small in the context of the whole train. Hence, for the purposes of this paper we do not assess energy indices.

- Suspension deflection index, $J_{2}$ : For the suspension deflection vector

$$
\begin{aligned}
\underline{z_{D}}(t) & =\left[z_{v b 1}(t) z_{v b 2}(t)\right]^{T} \\
& =\left[z_{b 1}-\left(z_{v}+l_{v} \beta_{v}\right) z_{b 2}-\left(z_{v}-l_{v} \beta_{v}\right)\right]^{T}
\end{aligned}
$$

where $z_{v b 1}$ and $z_{v b 2}$, are respectively, the deflection of the leading and trailing suspensions, the performance index $J_{2}$ is defined following the three-sigma rule as

$$
J_{2}=\max _{i=1,2}\left[M_{D, i}+3 \sigma_{D, i}\right]
$$

where $M_{D, i}$ is the $i$-th entry of the vector

$$
\underline{M_{D}}=\left[\max _{\dot{f}_{w z}, t>0}\left|z_{v b 1}(t)\right| \max _{\dot{f}_{w z}, t>0}\left|z_{v b 2}(t)\right|\right]^{T}
$$

which is the vector of the maximum deflection of the leading and trailing secondary suspensions developed during the transitional response to the deterministic track input $f_{w z}$. Moreover, $\sigma_{D, i}$ in Equation 8 is the root-mean-square of the entries of $\underline{z_{D}}$ in response to the stochastic track irregularities $\delta_{z}(t)$ and is calculated by using the same methods described for ride quality assessment. A typical value for the maximum allowable suspension deflection index $J_{2}$ is 3.5 [cm] [5].

- Active force index, $J_{3}$ : Similarly to the calculation of $J_{2}$, for the active forces demanded by the control systems of the leading and trailing suspensions, $F_{c L}$ $\left(F_{c 1}\right)$ and $F_{c T}\left(F_{c 2}\right)$, respectively,

$$
\underline{F_{c}}(t)=\left[F_{c L}(t) F_{c T}(t)\right]^{T}=\left[F_{c 1}(t) F_{c 2}(t)\right]^{T}
$$

the performance index $J_{3}$ is defined as

$$
J_{3}=\max _{i=1,2}\left[M_{F c, i}+3 \sigma_{F c, i}\right]
$$

where $M_{F c, i}$ is the $i$-th entry of the vector

$$
\underline{M_{F c}}=\left[\max _{\dot{f_{w z}}, t>0}\left|z_{F c 1}(t)\right| \max _{\dot{f}_{w z}, t>0}\left|z_{F c 2}(t)\right|\right]^{T}
$$

which is the vector of the maximum peak force required by the control systems to the leading and trailing actuators during the transitional response to the deterministic track input, $f_{w z} \cdot \sigma_{F c, i}$ is the root-mean-square of $F_{c, i}$ in response to the stochastic track irregularities and is calculated by using the same methods defined before for ride quality assessment. 


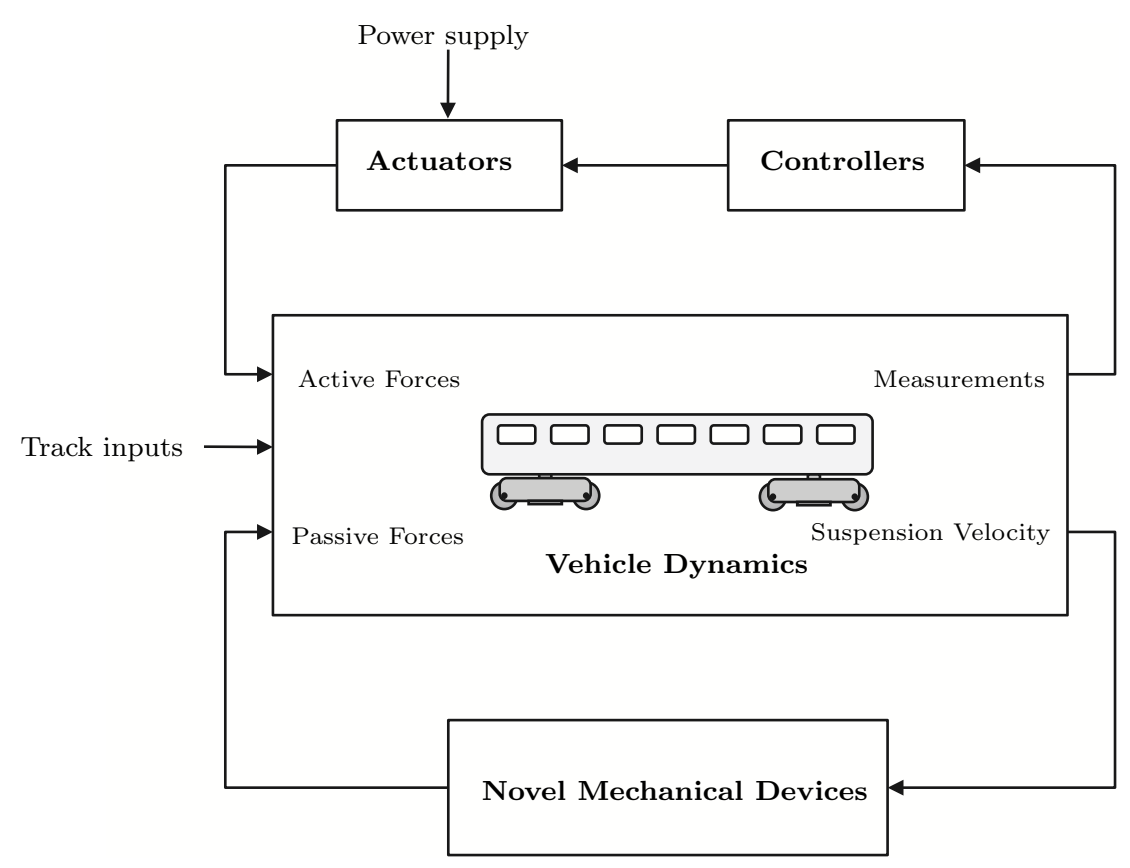

Figure 4. General scheme of the integrated suspension.

\section{Novel mechatronic suspensions incorporating inerters}

From the control perspective, the design of passive suspensions using inerters (e.g. mechanical, hydraulic) is supported on passive linear control and mechanical network theory. Incorporating inerters to a passive suspension enables the implementation of mechanical networks with resonant and selective compensating features; that is, the poles of a spring-damper-inerter network admittance function can be complex [12]. Active solutions, on the other hand, are commonly designed by choosing from an extensive range of appropriate control strategies, which could in fact include compensation structures such as those synthesised by using springs, dampers and inerters. These rely upon the system's input and output ports as well as on inherent constraints, e.g. the available measurements, the location of the actuators, and the action/reaction condition for the application of the controlled forces. In order to be able to evaluate the quality of the innovative technology researched here, the control strategies required meticulous selection and formulation while excluding these which could be implemented by passive networks. With this, we aim to study the potential of using passive compensation for reducing active forces towards a cooperative hybrid control.

The investigation on the synergy expected from the mechatronic suspensions using inerters starts with the integration of active and passive configurations as depicted in the general block diagram from Figure 4. The novel mechatronic structures will produce $i$-th integrated forces in parallel to the front $(i=1)$ and rear $(i=2)$ airsprings of the form

$$
\hat{F}_{u, i}=\hat{F}_{p n, i}+\hat{F}_{c, i}
$$

where: $F_{p n, i}$ is the force applied by the inerter-based device (i.e. the passive part of the mechatronic suspension), and $F_{c, i}$ is the force applied by an ideally perfect actuator (i.e. the active part of the mechatronic suspension). Candidate structures of the passive networks and the active control strategies, together producing $F_{u, i}$, are described in the following. 


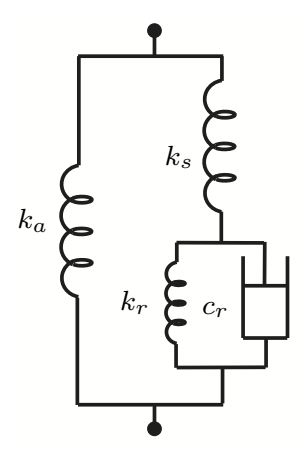

So

Airspring

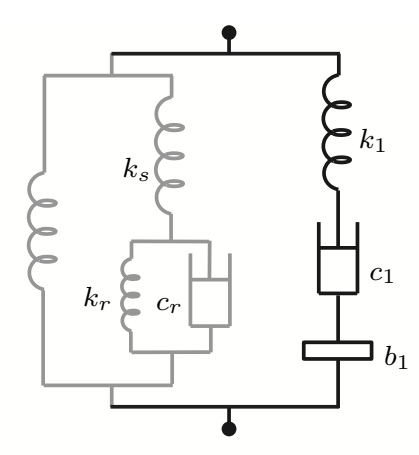

$\mathrm{S} 0 / / \mathrm{S} 1$

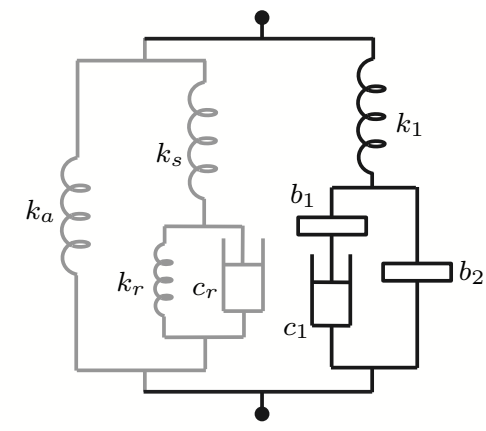

So//S2

Figure 5. Passive suspensions: Conventional passive suspension S0 (airspring) with inerter-based candidate layouts $\mathrm{Si}$ in parallel (for $i$ the structure identifier).

\subsection{Candidate inerter-based passive suspensions}

Mechanical and hydraulic inerter devices with equivalent models in mechanical networks comprising ideal springs, dampers and inerters were chosen for this study. Figure 5 contains the layouts $\mathrm{S} n$ of the equivalent inerter-based networks. A mechanical network defined this way, is linearly characterised by its admittance function $\mathrm{Y}_{p n}(s)$ and thus, can be said to develop passive forces in response to the relative velocity of the network terminals, i.e.

$$
\hat{F}_{p n, i}=\mathrm{Y}_{p n}(s) s\left(\hat{z}_{b, i}-\left(\hat{z}_{v}+(-1)^{i-1} l_{v} \hat{\beta}_{v}\right)\right)
$$

with the sub-index ' $i$ ' (with $i=1,2$ ) identifying the front and rear suspensions and bogies.

The mechanical structures in Figure 5 are composed by the conventional airspring mechanical model S0 and the inerter-based network layout $\mathrm{S} n$, with $n$ the structure identifier (notice that S1 and S2 look bold in the figure). The spring $k_{1}$ common to the layouts, implicitly includes the end-stiffness $k_{e}$ of the bushes that would be attached to both ends of the novel device and the vehicle body and bogies (typically, $k_{e}=3.5 \times 10^{6}\left[\mathrm{Nm}^{-1}\right]$ and thus $k_{1} \leq 3.5 \times 10^{6}\left[\mathrm{Nm}^{-1}\right]$ ).

Layout $\mathrm{S} 1$ is an equivalent for a mechanical inerter device $[12,15]$. The network model includes parasitic damping/friction and stiffness effects of the device, respectively, in $c_{1}$ and $k_{1}$. Sensible parameter values for the parasitic effects for the inerter sizes we use here are around $c_{1}=c_{b 1}=1 \times 10^{4}\left[\mathrm{Nsm}^{-1}\right]$, and $k_{1}=k_{b 1}=k_{e}$. It is worth noting, however, that the parasitic effects of a mechanical inerter itself, in terms of damping (or frictions) and stiffnesses, depend on the physical implementation of the inerter device. We consider this single case only. Furthermore, we decided not to constrain $c_{1}$ and $k_{1}$ to $c_{b 1}$ and $k_{b 1}$ (the coefficients for modelling the parasitic effects [15]), respectively, but instead to include them with the set of design parameters. This converts $\mathrm{S} 1$ in a spring-damper-inerter mechanical network with free stiffness, damping an inertance parameters. That enables a more expanded view of the inerter potential as an element of more complex mechanical devices. Layout S2, on the other hand, corresponds to one of the embodiments presented with the damping and inertial hydraulic device invention ([16]-Figures 16 and 20), with end-stiffness modelled in series. 


\subsection{Control strategies for the active suspensions}

Figure 6 shows a classification of the active control strategies chosen in this paper for vertical ride quality enhancement, which also considers the conflicts commonly arising in mechatronic control design. The first level of the diagram identifies active and passive strategies for ride quality enhancement, with the latter directly associated to mechanical networks including inerters. The lowest level shows that local control strategies are complemented by suspension deflection active regulation.

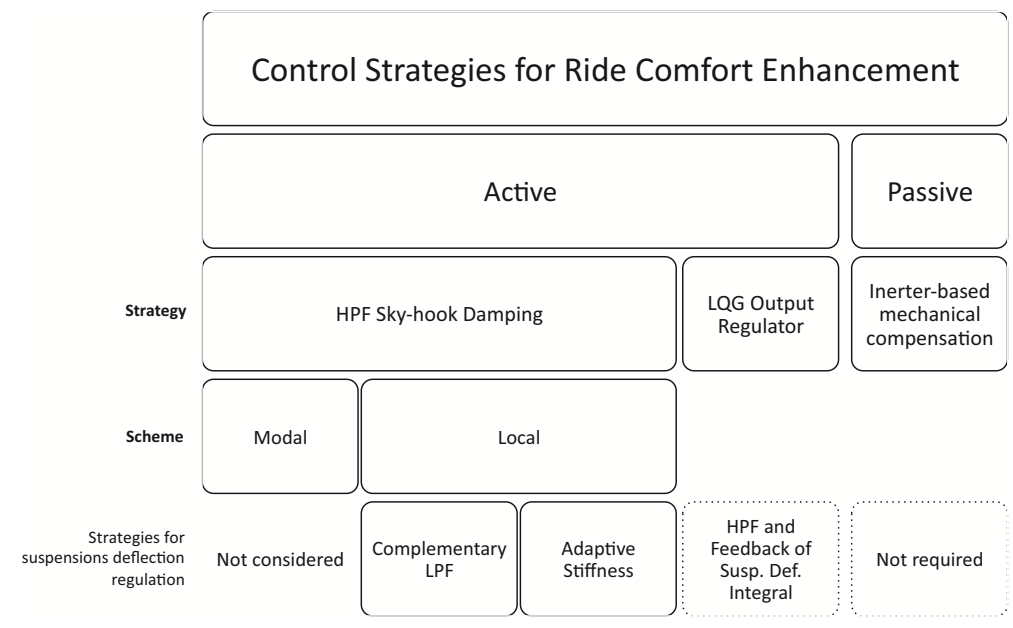

Figure 6. Classification of the control strategies for the mechatronic suspensions.

For active suspensions, the selection in Figure 6 is led by modifications of the well known 'skyhook' damping strategy — absolute velocity feedback - [41], which is an intuitive output-based suspension design strategy. Most of the variants of the skyhook damping implementation in Figure 6 are well known configurations, which have been already reported in the literature for railway suspension applications. In addition, another form of implementation of the local HPF skyhook damping is presented here. This consists in complementing the basis strategy for ride quality with the herein designated 'Adaptive Stiffness' control law for suspension deflection regulation. 'Adaptive Stiffness' is a slightly intuitive strategy inspired by the passivity of the system. This is a nonlinear and rather simple strategy based on the vehicle's absolute velocity, conceived as a novel modification of the potential energy function of the mechanical (Euler-Lagrange) system. This would enable more generalised conclusions. Notice also that from the energy viewpoint for our essentially Euler-Lagrange system, incorporating pure inerters to the suspensions implies kinetic energy modification whilst implementations of local skyhook damping control as presented here, target both potential energy and dissipation function modification. With this basis, this is considered a set of output-based control strategies of adequate relevancy to conclude on the potential of the inerter concept in novel mechatronic suspensions.

In particular for these output-based strategies, which would act together with an inerter-based passive structure, we define a multiobjective optimisation problem per combination as:

$$
\text { obj : } \min \left({\underline{J_{1}}}^{\text {sup }}, J_{3}, J_{2}\right)
$$

in order to adjust the parameters of the integrated configuration for optimal performance and practical requirement satisfaction. This considers the least ride quality penalisation index ${\underline{J_{1}}}^{\text {sup }}$, together with the design conflict indices $J_{2}$ and $J_{3}$. The 
nonconvex optimisation problems defined that way were solved for the parameters of every configuration by iteratively running genetic algorithms. In specific, we used the function gamultiobj from MATLAB ${ }^{\circledR}$ Global Optimization Toolbox [42] with initial population sets refined from previous optimisation runs. By setting a range of realistic ranges of values for the mechanical components (springs, dampers and inerters) as bound constraints, the algorithm found a local Pareto for the multiobjective problem formulated with every configuration, whose optimisation level was acceptable for the searched results.

Besides output-based (or skyhook damping-based) control strategies, a convenient modification of the standard implementation of LQR-output feedback - from the branch of model-based optimal control - is also proposed. This would complete a significant set of active control configurations for the study. A description on the individual active control strategies follows.

\subsubsection{Output-based control strategies: HPF Skyhook Damping}

The so-called 'skyhook damping' strategy by Karnopp [41] consists of feeding back absolute velocity measurements of the sprung mass to apply control forces $F_{c}$ to the system. We implemented it by high-pass filtering (HPF) the measured variable as in $[5,33]$ to prevent steady-state offsets in the suspensions' deflection when the vehicle transverses deterministic tracks with non-zero profile velocity (e.g. a gradient as the one described before). For the strategy, the active control force is defined, in general, as

$$
F_{c}=-c_{s k y} \dot{\tilde{x}}
$$

with $\dot{\tilde{x}}$ the high-pass filtered velocity $\dot{x} ; \dot{x}$ may refer to either a linear or rotational velocity. Here, the high-pass filter chosen for all the implementations was as a second order Butterworth filter, with a corner frequency $f_{c}$ defined accordingly in each configuration. In particular, two different configurations for implementing skyhook damping were used: local and modal configurations.

- Local configuration: feeds back the high-pass filtered velocity of the vehicle body, $\dot{z}_{v L}$ and $\dot{z}_{v T}$, measured at the actuators' location, with a 'damping' gain $c_{s k y}=$ $K_{l}$. (Note that the sub-index $L$ is a label for a measurement at the leading position, and $T$ at the trailing - both right above the actuators). Moreover, this implementation may include, as here, control components for suspension regulation. Here, we use complementary filtering [33] and the novel adaptive stiffness [28] (Figure 6), separately, as alternatives to ease the ride quality versus the suspension deflection trade-off [34].

HPF skyhook damping with complementary LPF (Low-Pass Filter) defines the control forces in the Laplace domain:

$$
\hat{F}_{c, i}=-K_{l}\left(G_{\mathrm{HPF}}(s) s \hat{z}_{v, i}+G_{\mathrm{LPF}(s)} \hat{z}_{v b, i}\right)
$$

with $i=1,2$ denoting leading and trailing variables, respectively, $z_{v b, i}$ the $i$-th suspension travel, and

$$
G_{\mathrm{HPF}(s)}+G_{\mathrm{LPF}(s)}=1
$$

On the other hand, HPF skyhook damping with adaptive stiffness, a novel strategy not used before for suspension regulation [28], is a local control strategy 
which establishes nonlinear control forces in the time domain of the form:

$$
F_{c, i}(t)=-K_{l} \dot{\tilde{z}}_{v, i}(t)+\kappa\left|\dot{z}_{v, i}(t)\right| z_{v b, i}(t)
$$

with $\kappa$ another design parameter.

- Modal implementation [5]: as its name suggests, the vehicle modes are considered separately in the definition of the control strategy. Hence, a modal control strategy is easily obtained by feeding back, through different loops, the HPF measurements of the vehicle body bounce $\left(z_{v}\right)$ and pitch $\left(\beta_{v}\right)$ velocities. This allows the definition of different values for the bounce and pitch 'damping' coefficients, $c_{s k y_{b}}$ and $c_{s k y_{\rho}}$ (or $K_{b}$ and $K_{\rho}$ to avoid confusion with passive parameters), respectively, as well as for the corner frequency of the respective high-pass filter, $f_{c_{b}}$ and $f_{c_{\rho}}$. This way, the active forces' bounce and pitch components, $\left(\hat{F}_{c}\right)_{b}$ and $\left(\hat{F}_{c}\right)_{\rho}$, respectively, can be written in the Laplace domain as:

$$
\begin{aligned}
& \left(\hat{F}_{c}\right)_{b}=-K_{b} G_{\mathrm{HPF}}^{f_{c b}}(s) s \hat{z}_{v} \\
& \left(\hat{F}_{c}\right)_{\rho}=-K_{\rho} G_{\mathrm{HPF}}^{f_{c \rho}}(s) s \hat{\beta}_{v}
\end{aligned}
$$

for active forces commanded to the leading $(i=1)$ and trailing $(i=2)$ suspension actuators given as

$$
\hat{F}_{c, i}=\left(\hat{F}_{c}\right)_{b}+(-1)^{i-1} l_{v}\left(\hat{F}_{c}\right)_{\rho}
$$

\subsubsection{Model-based optimal control: LQG HPF-Output Feedback Regulator}

Optimal control was implemented as the fourth active control strategy in this study as depicted in Figure 7. Individual problems were formulated to calculate the optimal regulator gain matrix $\mathbf{K}_{u}$ and the optimal estimator gain matrix $\mathbf{K}_{e}$ of the railway vehicle equipped with different inerter-based passive suspensions. Passive suspension parameters were pre-optimised and fixed for the vehicle equipped with passive suspensions only, with $\min \left({\underline{J_{1}}}^{\text {sup }}\right)$ as objective function (refer to Table 2). Then, the separation principle [43] was used accordingly and the corresponding Riccati equations were computationally solved.

The linear-quadratic output regulator problem was initially formulated as the minimisation of the performance measure given in the expected value of a quadratic function in terms of the system's assessment output and the control input. That is

$$
J_{\mathrm{LQR}}=\lim _{t \rightarrow \infty} \mathrm{E}\left[\underline{\chi^{T}}(t) \mathbf{Q} \underline{\chi}(t)+\eta \underline{F}^{T}(t) \mathbf{R} \underline{F_{c}}(t)\right]
$$

for both $\mathbf{Q}$ and $\mathbf{R}$ real-positive definite weighting matrices, and $\eta$ a real-positive value determining the particular case of solving a 'cheap control problem' [43].

Under this formulation, the vector $\chi(t)$ is the assessment output vector consisting of the acceleration at both longitudinal ends of the vehicle body (where the ride quality is lower), together with the time-domain integral of the suspensions' deflection to prevent excessive suspension deflection, and assumed available for 
measurement:

$$
\underline{\chi}(t)=\left[\begin{array}{c}
\ddot{z}_{v L}(t) \\
\ddot{z}_{v T}(t) \\
\int_{0}^{t} z_{D L}(t) d t \\
\int_{0}^{t} z_{D T}(t) d t
\end{array}\right]=\left[\begin{array}{c}
\ddot{z}_{v L}(t) \\
\ddot{z}_{v T}(t) \\
x_{i D 1}(t) \\
x_{i D 2}(t)
\end{array}\right]
$$

Introducing the time-domain integral of the suspensions' deflection in the performance measurement in Equation 23, as well as omitting the acceleration measurement at the middle position of the vehicle body, were found to produce a better trade-off between the assessed performance indices: ride quality, suspension deflection and active forces indices - as compared with including simply the suspensions' deflection as in $[5,32]$.

Given the fact that not all the states should be available to measure and feedback, the solution of the optimal regulator problem consisted in finding the feedback control law for the suspension's active forces minimising Equation 23, defined as

$$
\underline{F_{c}}(t)=-\mathbf{K}_{u} \underline{\tilde{x}^{\prime}}(t)
$$

with $\underline{\tilde{x}^{\prime}}(t)$ the optimal estimate of $\underline{x^{\prime}}(t)$. The latter was calculated by using the conventional Kalman estimator for the stochastic system:

$$
\begin{array}{r}
\underline{\dot{x}^{\prime}}(t)=\mathbf{A} \underline{x^{\prime}}(t)+\mathbf{B}_{u} \underline{u}(t)+\underline{\xi}(t) \\
\underline{y_{m}}(t)=\mathbf{C}_{m} \underline{x^{\prime}}(t)+\mathbf{D}_{u} \underline{u}(t)+\underline{\theta}(t)
\end{array}
$$

For which we had:

- The measured output: $\underline{y_{m}}(t)=\underline{y_{\ddot{z} v}}(t)=\left[\ddot{z}_{v}+l_{v} \ddot{\beta}_{v}, \ddot{z}_{v}, \ddot{z}_{v}-l_{v} \ddot{\beta}_{v}\right]^{T}$

- The additive process noise given by $\underline{\xi}(t)=\mathbf{B}_{\dot{\delta}}(t) \underline{\dot{\delta}_{m}}(t)$, where $\underline{\dot{\delta}_{m}}(t)$ is the change rate of the track irregularities.

- The measurement noise vector $\underline{\theta}(t)$ received low importance as it was not included in any of the other control configurations studied here.

- The vector $\underline{u}(t)$ equivalent to the active control force vector, $\underline{u}(t): \triangleq \underline{F_{c}}(t)$ from Equation 25.

The design trade-off curves required for this analysis were obtained by assigning values of $\eta$ from Equation 23 within a reasonable range, enabling with this the adjustment of the control force penalisation for the optimisation cost function $J_{L Q R}$. It was varied from 0.25 to $10^{4}$; a value of $\eta=0.25$ enabled high variance active forces, whilst $\eta=10^{4}$ set a very strong penalisation on the control force amplitude causing them to be practically null. On the other hand, the calculation of $\mathbf{K}_{u}$ and $\mathbf{K}_{e}$ was performed by using the functions LQOutputRegulatorGains and LQEstimatorGains, respectively, from Mathematica ${ }^{\circledR}$. For this, the assessment outputs and the control forces weighting matrices ( $\mathbf{Q}$ and $\mathbf{R}$, respectively), appearing in the cost function $J_{\mathrm{LQR}}$ in Equation 23, were defined as

$$
\mathbf{Q}=\mathbf{Q}^{\mathrm{S}}=\left[\begin{array}{cc}
\mathbf{Q}_{J_{1}}^{\mathrm{S}} & \mathbf{0} \\
\mathbf{0} & \mathbf{Q}_{\sigma_{S D i}}^{\mathrm{S}}
\end{array}\right]
$$

with 


$$
\mathbf{Q}_{J_{1}}^{\mathrm{S}}=\left[\begin{array}{cc}
\frac{1}{\left(J_{1 L}^{\mathrm{S}}\right)^{2}} & 0 \\
0 & \frac{1}{\left(J_{1 T}^{\mathrm{S}}\right)^{2}}
\end{array}\right], \quad \mathbf{Q}_{\sigma_{\mathrm{SDi}}}^{\mathrm{S}}=\left[\begin{array}{cc}
\frac{1}{\left(\sigma\left(x_{i D 1}^{\mathrm{S}}\right)\right)^{2}} & 0 \\
0 & \frac{1}{\left(\sigma\left(x_{i D 2}^{\mathrm{S}}\right)\right)^{2}}
\end{array}\right]
$$

and

$$
\mathbf{R}=\left[\begin{array}{cc}
\frac{1}{\left(\sigma_{F c}^{\operatorname{Max}}\right)^{2}} & 0 \\
0 & \frac{1}{\left(\sigma_{F c}^{\text {Max }}\right)^{2}}
\end{array}\right]
$$

This basically follows Bryson's rule [44]. The super-index ' $\mathrm{S}$ ' in Equation 28 (and therefore in the entries of $\mathbf{Q}_{J_{1}}^{\mathrm{S}}$ and $\mathbf{Q}_{\sigma_{S D i}}^{\mathrm{S}}$ ) was used to denote 'suspension layout', i.e. S0, S1, S2. Thus, for every configuration F\&S0, F\&S1, and F\&S2, a different $\mathbf{Q}$ matrix was calculated; the indicated r.m.s. values $J_{1 L, T}^{\mathrm{S}}$ and $\sigma\left(x_{i D 1,2}^{\mathrm{S}}\right)$ were obtained for the vehicle with every candidate layout. Defining $\mathbf{Q}$ this way, normalises the assessment outputs according to their values for every particular case, and sets a standard for the calculation of the optimal solution to allow for comparisons. On the other hand, the value $\sigma_{F_{c}}^{\operatorname{Max}}$ for the definition of the matrix $\mathbf{R}$ was based on the consideration that the maximum value allowed for the variance of the control forces applied at the leading and trailing suspensions was $\sigma_{F_{c}}^{\mathrm{Max}}=$ $4[\mathrm{kN}]$. For the optimal estimator, the autocorrelation matrices of the input and measurement noises, were defined as $\mathbf{W}=p \mathbf{I}_{4 \times 4}$ (with $p=(2 \pi)^{2} \Omega_{z} v=5.43 \times$ $10^{-4}\left[\left(\mathrm{~m} \mathrm{~s}^{-1}\right)^{2}\right]$ the amplitude of the linear frequency autocorrelation function of the track input $\left.\dot{S}_{t}^{\dot{\delta}_{z}}\left(\omega_{t}\right)\right)$, and $\mathbf{V}=v_{\theta}^{2} \mathbf{I}_{4 \times 4}$, with $v_{\theta}$ arbitrarily defined as a very low value under assumption of almost 'perfect' measurements $\left(v_{\theta}=5 \times 10^{-6}\right)$.

Finally, due to the nature of the Kalman estimator and for practical implementation to account also for deterministic track features, we considered to remove the low-frequency components of the output-based estimated states. Hence, the inclusion of the 'HPF' acronym in the configuration name. Figure 7 illustrates the configuration for the LQG HPF-Output Feedback Regulator. Thus, the feedback on the system's dynamic states was implemented on the filtered estimated states $\tilde{\tilde{x}_{z}^{\prime}}\left(\right.$ from $\tilde{\tilde{x}^{\prime}}=\left[\begin{array}{c|c}\tilde{x_{z}^{\prime}} & \tilde{\tilde{x}_{i D}^{\prime}}\end{array}\right]^{T}$ ), throughout the regulator gain sub-matrix, $\mathbf{K}_{c z}$ (from $\mathbf{K}_{c}=\left[\mathbf{K}_{c z} \mid \mathbf{K}_{c i D}\right]$ ). In particular, the feedback associated with the gain sub-matrix $\mathbf{K}_{c i D}$ to regulate the suspension travel was directly performed on the time-integral of the measured suspension's deflection; i.e. the estimation of $\underline{x}_{i D}(t)$ was not decided for feedback. As an alternative, the estimated variables for $\underline{x_{i D}}(t)$ can be extracted before performing high-pass filtering on the estimated states and used for feedback; this would be determined by practical implementation convenience. The drawback of doing this modification after designing the gain estimation matrix $\mathbf{K}_{e}$ is that the estimation error is increased and thus the solution is suboptimal and relies on the choice of the filter corner frequency value, $f_{c}$.

\section{Results and Discussion}

Before discussing results for the novel mechatronic suspensions, we present details on the performance of the railway vehicle with passive suspensions only, i.e. with the conventional secondary suspension and incorporating inerter-based elements without active control. 


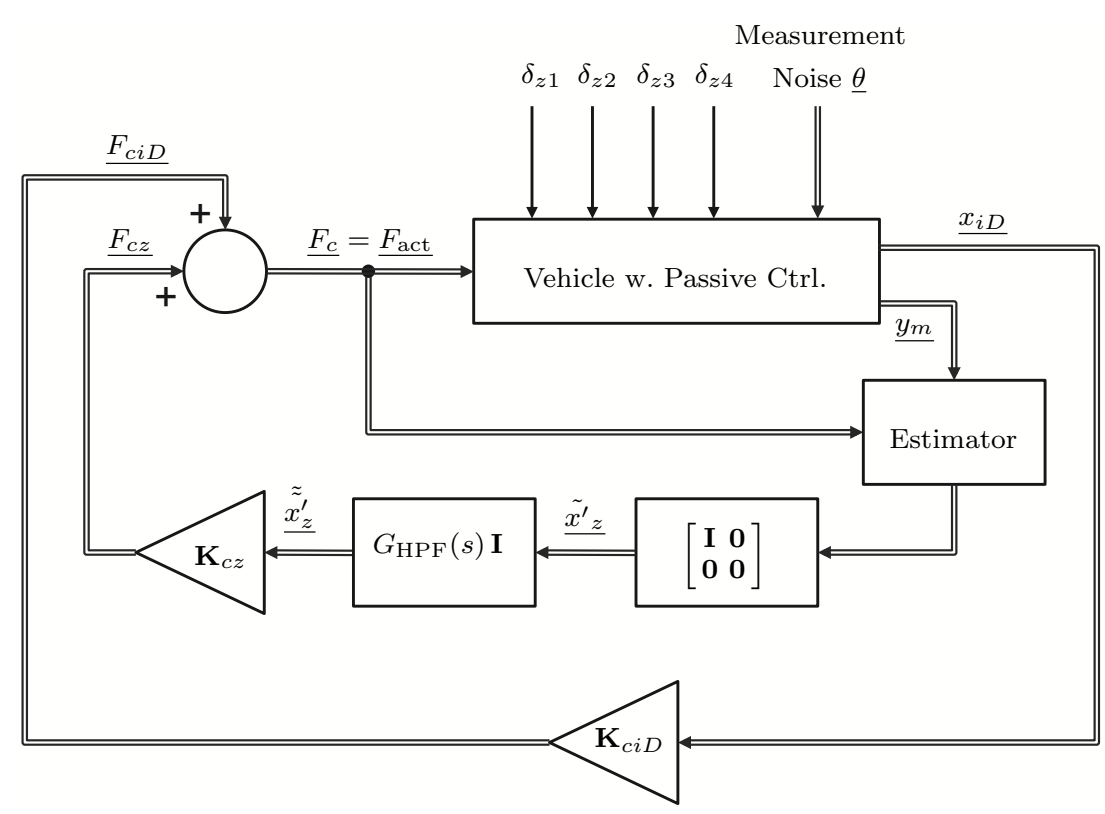

Figure 7. Block diagram for the LQG HPF-Output Feedback Regulator.

\subsection{Passive System Performance}

The optimal performance of the railway vehicle equipped with passive secondary suspensions only is as depicted in Table 2, whose parameters are shown in Table 3 for a reference. It can be checked from Table 2 that the configurations incorporating inerters provide up to $19 \%$ of ride quality enhancement, as compared with the results for the system with the conventional secondary suspension, S0. Besides, the suspension deflection index is reduced when introducing inerter-based configurations. This provides an advantage for the active suspensions design and will be evidenced in the following sub-section.

Table 2. Optimisation results for the passive suspensions

\begin{tabular}{ccclc}
\hline & \multicolumn{3}{c}{ Ride quality } & Other Indices \\
\cline { 2 - 5 } Config. & $J_{1 L}[\% \mathrm{~g}]$ & $J_{1 M}[\% \mathrm{~g}]$ & $J_{1 T}[\% \mathrm{~g}]$ & $J_{2}[\mathrm{~cm}]$ \\
\hline \hline S0 & 3.09 & 1.36 & $\mathbf{3 . 6 0}$ & 3.4 \\
S0//S1 & 2.69 & 1.39 & $\mathbf{2 . 9 2}(19 \%)^{a}$ & 2.9 \\
S0//S2 & 2.66 & 1.32 & $\mathbf{3 . 0 8}(14 \%)^{a}$ & 3.2 \\
\hline
\end{tabular}

a Percentage of improvement in the ride quality index, ${\frac{J_{1}}{3 .}}^{\text {sup }}$, with respect to the passive conventional suspension: ${\underline{J_{1}}}^{\text {sup }}=\frac{1}{3.60}[\% \mathrm{~g}]$.

Table 3. Parameters for the results in Table 2 (passive suspensions)

\begin{tabular}{lc}
\hline Layout & Parameter values \\
\hline \hline $\mathrm{S} 0 / / \mathrm{S} 1$ & $c_{1}=42452, b_{1}=5411$ \\
$\mathrm{~S} 0 / / \mathrm{S} 2$ & $c_{1}=26455, b_{1}=1870, b_{2}=243$ \\
\hline$b_{1,2}[\mathrm{~kg}], k_{2}\left[\mathrm{Nm}^{-1}\right], c_{1}\left[\mathrm{Nsm}^{-1}\right]$
\end{tabular}

\subsection{Vehicle Performance with novel-mechatronic secondary suspensions}

Pareto optimal solutions were obtained for all the different control configurations enlarged with inerter-based structures, i.e. the novel mechatronic suspensions we study in this paper. The corresponding Pareto optimal plots for ${\underline{J_{1}}}^{\text {sup }}$ versus $J_{2}$, and ${\underline{J_{1}}}^{\text {sup }}$ versus $J_{3}$, are shown in Figures 8-11. Notice that from here, the label 
$\mathrm{F} \& \mathrm{~S} 0$ refers to the conventional implementation of an active suspension, and F\&S1, and F\&S2, are adopted to refer to the hybrid suspensions integrating the novel passive structures $\mathrm{S} 1$ and $\mathrm{S} 2$, in parallel to the conventional airspring S0 (Figure 5). Therefore, the identifier ' $F$ ' stands for 'active forces applied', and the control strategy employed will be specified accordingly where corresponds.

The integration of inerter-based suspensions with each control strategy showed similar characteristics in the trade-off curves for the least ride quality index, $J_{1}{ }^{\text {sup }}$, versus the active forces index, $J_{3}$, and similarly for the trade-off curves for the least ride quality index, ${J_{1}}^{\text {sup }}$, versus the suspension deflection index, $J_{2}$. Benefits of inerter-based suspensions are more evident for low to average ride quality improvements. In fact, for higher dissipation conditions, the effects of the inerter may become negative. This agrees with previous observations on systems equipped with passive suspensions only, for which the mechanical inerter fail to benefit the softer suspensions [8].

For comparison purposes, we explore results for three common design criteria based upon important performance enhancement achievements and conventional design constraints (i.e. typical values of suspension travel and maximum active force employed to size real actuators in practical implementations [5]):

- Criterion I: $30 \%$ of ride quality improvement w.r.t. the performance of a vehicle with conventional suspensions, i.e. ${\underline{J_{1}}}^{\text {sup }}=2.52[\% \mathrm{~g}]$

- Criterion II: maximum deflection index of $J_{2}=3.5[\mathrm{~cm}]$

- Criterion III: maximum active force index of $J_{3}=10[\mathrm{kN}]$
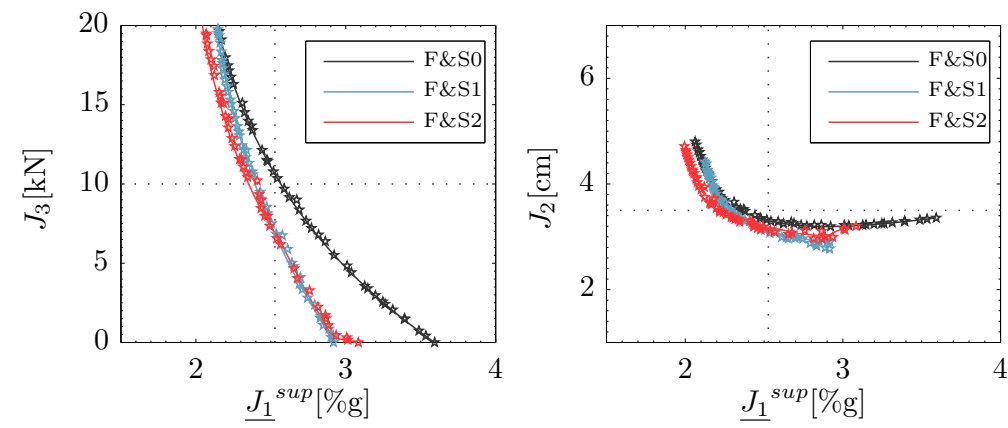

(a) Least ride quality, ${\underline{J_{1}}}^{\text {sup }}$, versus act-(b) Least ride quality, ${\underline{J_{1}}}^{\text {sup }}$, versus susive force index, $J_{3}$.

pension deflection index, $J_{2}$.

Figure 8. Comparison of the design trade-off curves for the vehicle with 'Local Sky-hook Damping with Complementary Filtering' and the candidate layouts S1-S2 from Figure 5, contrasted with the conventional mechatronic suspension.

Tables 4-6 summarise the results for Criteria I-III, respectively, for the different configurations of novel mechatronic suspensions individually integrated with each active control strategy. Table 7 shows the parameter values obtained from the genetic algorithms to produce the results in Table 4 for the reader reference. Parameter sets for the linear-quadratic HPF output regulator and for Criteria II and III were omitted for space reasons. Following results for Criterion I, Table 4 shows that:

(1) Introducing inerter-based suspensions as S1 and S2 in parallel to the airsprings integrated with active suspensions (i.e. implementing F\&S1 or F\&S2 with ideal actuators), with any of the four control strategies, helps to reduce $J_{3}$ as compared to the the respective conventional active configuration F\&S0. In fact, $J_{3}$ can be reduced by at least $35 \%$, depending on the control 

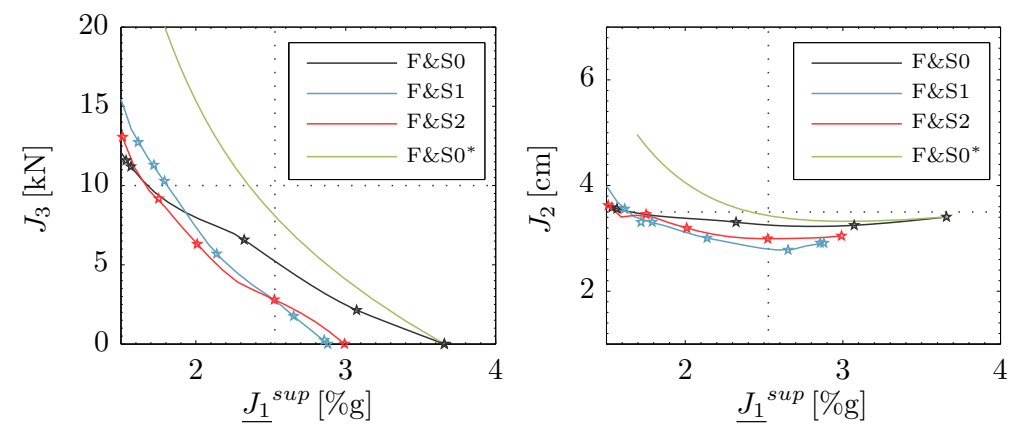

(a) Least ride quality, $J_{1}$ sup , versus act-(b) Least ride quality, $J_{1}$ sup , versus susive force index, $J_{3}$.

pension deflection index, $J_{2}$.

Figure 9. Comparison of the design trade-off curves for the vehicle with 'Local Sky-hook Damping with Adaptive Stiffness' and the candidate layouts S1-S2 from Figure 5, contrasted with the conventional mechatronic suspension. $\mathrm{F} \& S 0^{*}$ stands for the trade-off curve of the system without the adaptive stiffness component in the active control strategy.
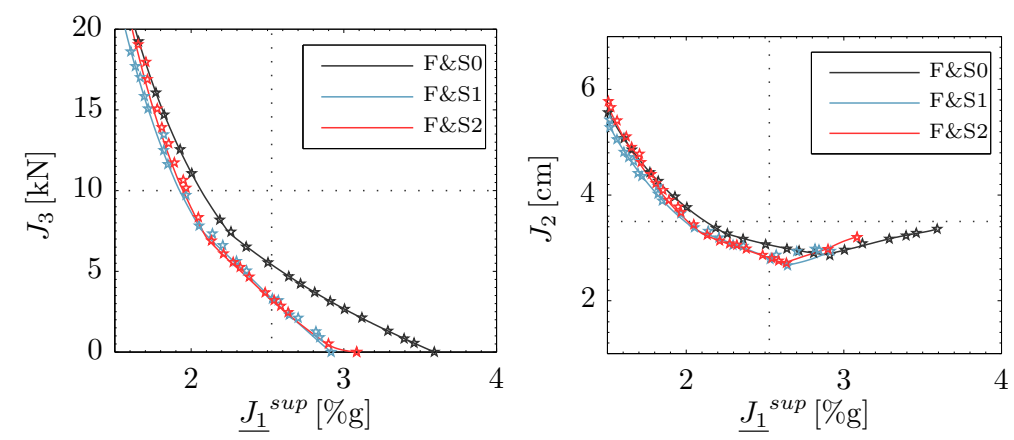

(a) Least ride quality, ${\underline{J_{1}}}^{\text {sup }}$, versus act-(b) Least ride quality, ${\underline{J_{1}}}^{\text {sup }}$, versus susive force index, $J_{3}$.

pension deflection index, $J_{2}$.

Figure 10. Comparison of the design trade-off curves for the vehicle with 'Modal HPF Sky-hook Damping' and the candidate layouts S1-S2 from Figure 5 , contrasted with the conventional mechatronic suspension.

Table 4. Result comparison for each active strategy according to Criterion I (30\% of improvement on ${\underline{J_{1}}}^{\text {sup }}$ w.r.t. the ride quality of the vehicle with conventional passive suspensions, $\underline{\text { SO.) }}$

\begin{tabular}{|c|c|c|}
\hline \multirow[b]{2}{*}{ / Configuration: } & \multicolumn{2}{|c|}{$\begin{array}{l}\text { Improvement } \\
\text { on } J_{3}\end{array}$} \\
\hline & F\&S1 & F\&S2 \\
\hline Modal HPF skyhook damping $\left(J_{3}=5.44[\mathrm{kN}]\right)^{a}$ & $38 \%$ & $41 \%$ \\
\hline $\begin{array}{l}\text { Local skyhook damping with } \\
\text { complementary filtering }\left(J_{3}=10.71[\mathrm{kN}]\right)^{a}\end{array}$ & $35 \%$ & $36 \%$ \\
\hline $\begin{array}{l}\text { Local HPF skyhook damping with } \\
\text { adaptive stiffness }\left(J_{3}=5.65[\mathrm{kN}]\right)^{a}\end{array}$ & $50 \%$ & $47 \%$ \\
\hline LQG-HPF output feedback regulator $\left(J_{3}=12.4[\mathrm{kN}]\right)^{a}$ & $35 \%$ & $36 \%$ \\
\hline
\end{tabular}

a $J_{3}$ value attained for the conventional active configuration F\&S0

strategy.

(2) Both, 'Modal HPF skyhook damping' and 'Local HPF skyhook damping with adaptive stiffness' control strategies, would demand lower forces to the actuators with any passive configuration.

(3) The configuration with 'Local HPF skyhook damping with adaptive stiffness' strategy was more improved by the insertion of the inerter-based suspensions. In fact, $J_{3}$ was reduced by a half for the configuration F\&S1.

(4) The suspension deflection index $J_{2}$ remains well below the limit of $3.5[\mathrm{~cm}]$. 

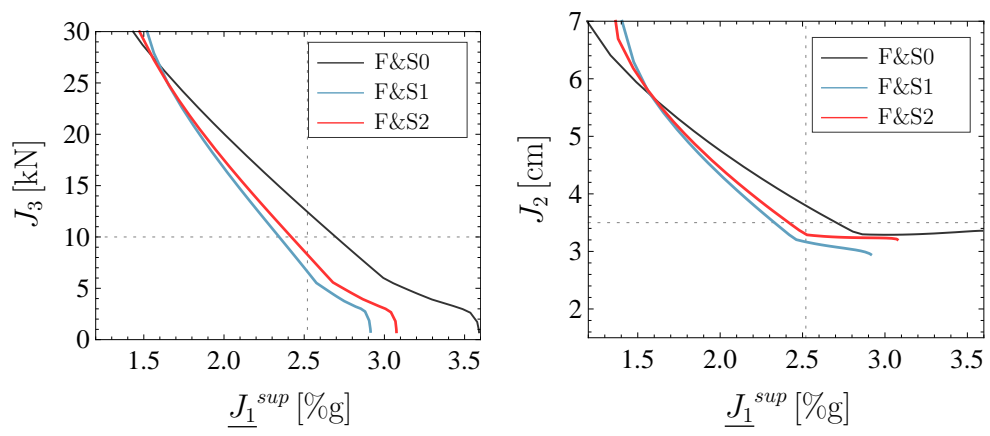

(a) Least ride quality, ${\underline{J_{1}}}^{\text {sup }}$, versus act-(b) Least ride quality, ${\underline{J_{1}}}^{\text {sup }}$, versus susive force index, $J_{3}$.

pension deflection index, $J_{2}$.

Figure 11. Comparison of the design trade-off curves for the vehicle with 'LQG HPF-Output Feedback Regulator' and the candidate layouts S1-S2 from Figure 5, contrasted with the conventional mechatronic suspension.

Table 5. Result comparison for each active strategy according to Criterion II $\left(J_{2}=3.5[\mathrm{~cm}]\right)$

\begin{tabular}{lrrr}
\hline & \multicolumn{3}{c}{ Improvement $^{a}$ on $J_{1}$ sup } \\
\cline { 2 - 4 } Control strategy / Configuration: & F\&S0 & F\&S1 & F\&S2 \\
\hline $\begin{array}{l}\text { Modal HPF skyhook damping } \\
\text { Local skyhook damping with }\end{array}$ & $41 \%$ & $45 \%$ & $44 \%$ \\
$\quad$ complementary filtering & $35 \%$ & $37 \%$ & $39 \%$ \\
$\quad \begin{array}{l}\text { Local HPF skyhook damping with } \\
\quad \text { adaptive stiffness }\end{array}$ & $54 \%$ & $53 \%$ & $54 \%$ \\
LQG-HPF output feedback regulator & $25 \%$ & $35 \%$ & $33 \%$ \\
\hline
\end{tabular}

${ }^{\text {a }}$ w.r.t. ${\underline{J_{1}}}^{\text {sup }}$ for the conventional passive configuration, S0.

Table 6. Result comparison for each active strategy according to Criterion III $\left(J_{3}=10[\mathrm{kN}]\right)$

\begin{tabular}{|c|c|c|c|}
\hline & \multicolumn{3}{|c|}{ Improvement $^{a}$ on $J_{1}$ sup } \\
\hline Control strategy / Configuration: & F\&S0 & $\mathrm{F} \& \mathrm{~S} 2$ & $\mathrm{F \& S} 4$ \\
\hline Modal HPF skyhook damping & $43 \%$ & $47 \%$ & $46 \%$ \\
\hline $\begin{array}{l}\text { Local skyhook damping with } \\
\text { complementary filtering }\end{array}$ & $29 \%$ & $34 \%$ & $35 \%$ \\
\hline $\begin{array}{l}\text { Local HPF skyhook damping with } \\
\text { adaptive stiffness }\end{array}$ & $53 \%$ & $50 \%$ & $54 \%$ \\
\hline LQG-HPF output feedback regulator & $25 \%$ & $35 \%$ & $33 \%$ \\
\hline
\end{tabular}

a w.r.t. $\underline{J}_{1}{ }^{\text {sup }}$ for the conventional passive configuration, S0.

Table 7. Parameters for the results in Table 4

\begin{tabular}{|c|c|c|}
\hline Control strategy & Layout & Parameter values \\
\hline Modal HPF skyhook damping & $\begin{array}{l}\text { F\&S0 } \\
\text { F\&S1 } \\
\text { F\&S2 }\end{array}$ & $\begin{array}{c}K_{b}=6000, K_{\rho}=37085 \\
K_{b}=1079, K_{\rho}=25198 \\
c_{1}=39252, b_{1}=3926 \\
K_{b}=311, K_{\rho}=23344 \\
c_{1}=26278, b_{1}=3068, b_{2}=238\end{array}$ \\
\hline $\begin{array}{l}\text { Local skyhook damping with } \\
\text { complementary filtering }\end{array}$ & $\begin{array}{l}F \& S 0 \\
F \& S 1 \\
F \& S 2\end{array}$ & $\begin{array}{c}K_{l}=4684, f_{c}=0.2797 \\
K_{l}=28635, f_{c}=0.2332, \\
c_{1}=33497, b_{1}=4083 \\
K_{l}=28834, f_{c}=0.2598 \\
c_{1}=27956, b_{1}=1955, b_{2}=253\end{array}$ \\
\hline $\begin{array}{c}\text { Local HPF skyhook damping with } \\
\text { adaptive stiffness }\end{array}$ & $\begin{array}{l}\text { F\&S0 } \\
\text { F\&S1 } \\
\text { F\&S2 }\end{array}$ & $\begin{array}{c}K_{l}=38260, \kappa=8.219 \times 10^{5} \\
K_{l}=30660, \kappa=1.2375 \times 10^{6} \\
c_{1}=40000, b_{1}=8354 \\
K_{l}=27930, \kappa=1.4936 \times 10^{6}, \\
c_{1}=24030, b_{1}=2256, b_{2}=206\end{array}$ \\
\hline
\end{tabular}

$b_{1,2}[\mathrm{~kg}], k_{2}\left[\mathrm{Nm}^{-1}\right], c_{1}\left[\mathrm{Nsm}^{-1}\right], f_{c}[\mathrm{~Hz}]$ 
Moreover, for Criterion II, Table 5 shows that:

(1) The configurations with 'Local HPF skyhook damping with adaptive stiffness' control strategy, with and without inerter-based devices, provide better effects in the ride quality than the other control strategies, followed by 'Modal HPF skyhook damping'. Up to $54 \%$ of reduction - hence, ride quality improvement - in the value for $J_{1}{ }^{\text {sup }}$ is attained with the former.

(2) All the mechatronic suspensions, excepting that with the 'Local HPF skyhook damping with adaptive stiffness' control strategy, are further improved by the inerter-based structures in terms of ride quality. For the 'Local HPF skyhook damping with adaptive stiffness' strategy, the improvements in $J_{1}{ }^{\text {sup }}$ are about the same for F\&S0, F\&S1, and F\&S2.

(3) The lower the improvement in ${\underline{J_{1}}}^{\text {sup }}$ given by the active suspensions alone with the airsprings (i.e. F\&S0), the higher the enhancement given by the insertion of either S1 or S2 in parallel to the airspring (i.e. F\&S1 or F\&S2, respectively).

Similar observations to these for Criterion II apply for the data contained in Table 6 for Criterion III, with 'Local skyhook damping with complementary filtering' and 'LQG-HPF output feedback regulator' control strategies being more benefited from the insertion of inerter-based suspensions. Furthermore, combining 'Local HPF skyhook damping with adaptive stiffness' with the structure S2 with either design criterion II or III would deteriorate the performance of the active control strategy under ideal actuation conditions.

\section{Integration Test in Advanced Simulation}

The simplified example model from the Manchester Benchmark [45, 46] available for the rail add-on module of SIMPACK (SIMPACK Wheel/Rail) was used, with some appropriate modifications, to examine the effects of integrating inerters to the active secondary suspensions of a more complex model. However, the type of vehicle considered for the Manchester Benchmark differs from that modelled for the studies presented earlier in this paper, particularly in the type of secondary suspensions of the models. The former, a 3D model considering all rigid and flexible modes of the vehicle, includes secondary suspensions comprising a parallel arrangement (shear) spring and damper, instead of airsprings. Because of the vehicles' differences, the optimal parameter design performed on the planar model from previous sections could not be directly applied on the Manchester Benchmark model. The same optimisation work performed on the side-view model of the vehicle used in advanced simulation, and which must include also the bending modes, should make this possible due to the decoupling between bounce and pitch modes from lateral, yaw and pitch modes. Nevertheless, this more complex model enables a qualitative validation of the results obtained for the planar model used within this paper.

\subsection{Implementation of the Integrated Suspension}

For this test, 'Modal skyhook damping with high-pass filtering' strategy was chosen to be integrated with the most simple inerter-based structure studied above (i.e. S1 in 5). Here, the purpose was to examine the effects of varying the inertance value and the control parameters on the vertical ride quality index $J_{1}$, and maximum r.m.s. value of the active forces among these applied at the leading and trailing (left and right) suspensions. Hence, this exercise considered only the stochastic irregu- 
larities of the track. The implementation of the inerter-based device was performed by using a control element, as its linear dynamic is approximated by a transfer function characterising its mechanical complex admittance. For this, measurement of the relative velocity of the vertical motion of each secondary suspension, no filtering and ideal actuation were required. An alternative to this, would have been to use SIMPACK force elements, but a new element to model the inerter element would have been required. For implementation of active suspensions with 'Modal HPF skyhook damping' control, accelerometers for measuring pitching and bouncing accelerations at the vehicle body centre of gravity were incorporated, as well as an actuator with perfect dynamic in parallel to each suspension. The acceleration measurements were integrated and filtered by second-order filters as described in Sub-section 4.2.1, with corner frequencies of $f_{c b}=0.225[\mathrm{~Hz}]$ and $f_{c \rho}=0.179[\mathrm{~Hz}]$ for the bounce and pitch measurements, respectively, which were the settings used in the previous section for the same configuration

\subsection{Simulation results and validation}

For this qualitative validation, manual tuning for vertical ride quality improvement was performed on the three design parameters considered: $K_{b}$ and $K_{\rho}$ for the control structure described by Equation 22, and $b_{1}$ for the inerter-based structure S1 in Figure 5. With this manual procedure, no value for the damping coefficient $K_{b}$, for a fixed value of the corner frequency $f_{c b}$, was found to benefit the ride quality. Thus, $K_{b}$ was set to zero and $K_{\rho}$ and $b_{1}$ were adjusted to the best possible values to obtain different sets of parameters, enabling the aimed comparisons.

Due to the difficulty of performing manual tuning, a very small but meaningful set of parameters $K_{\rho}-b_{1}$ was obtained after a trial-error procedure. In the same way, a good setting for the gain $K_{\rho}$ of the only active configuration was attained. Note that the baseline passive performance is different to that in the previous section, but the emphasis here is upon the performance of improvement.

Table 8. Performance indices with different settings for the model with novel suspensions in SIM-

\begin{tabular}{lcc}
\hline PACK & & \\
\hline Configuration Setting & $J_{1}^{\text {sup }}[\% \mathbf{g}]$ & Max. Force [kN] \\
\hline \hline Conventional & 5.71 & 0 \\
Only active (F) & 4.38 & 1.6 \\
(a) Only passive (S1) & 4.79 & 0 \\
(b) Novel mechatronic (F\&S0//S1) -Opt. setting 1 & 4.66 & 0.3 \\
(c) Novel mechatronic (F\&S0//S1) -Opt. setting 2 & 4.20 & 1.4 \\
\hline
\end{tabular}

Table 8 summarises the ride quality index ${\underline{J_{1}}}^{\text {sup }}$ and the maximum r.m.s. active force value for the corresponding time-domain responses. It shows that the r.m.s. value of the maximum stochastic active force required for achieving $23 \%$ of ride quality improvement with respect to the conventional vehicle is of is $1.6[\mathrm{kN}]$, without inerters (this value corresponds to the front-right suspension). Also, by using linear fitting on data shown in Table 8 , it is found that this maximum force value can be reduced in at least $39 \%$ to achieve the same ride quality. Table 9 shows that this is qualitatively similar to the results obtained from optimal settings of the same control configuration for the planar model. The same correspondence between outcomes from the two models is expected for the response to deterministic track profiles, as well as with other integrated suspension configurations. Further relevant tests were left for a more dedicated work on complex simulations in a future study. 
Table 9. Result comparison for $23 \%$ ride quality achievement in the planar model and the SIMPACK model

\begin{tabular}{lcc}
\hline Model: & Max. Force in conventional configuration & Max. Force Reduction \\
\hline \hline Planar Model & $727[\mathrm{~N}]$ & $46 \%$ \\
SIMPACK Model & $1600[\mathrm{~N}]$ & $39 \%$ \\
\hline
\end{tabular}

\section{Concluding Remarks}

Results from this paper contribute to the design of railway vehicle novel mechatronic suspensions. Analyses extracted from Tables 4-6 clearly reveal the potential of these inerter-based mechanical networks for enhancing the ride quality of a railway vehicle equipped with active suspensions, and for reducing the actuator size in the achievement of certain levels of improvement. Moreover, the outcomes indicate that the benefits for ride quality enhancement and active forces reduction provided by inerter-based suspensions do not depend strictly on the control strategy but on the degree of ride quality improvement with respect to the default passive configuration. This relates to the levels of relative effort demanded to the -idealactuators, that is, with respect to each control strategy active force index in conventional configurations. This remark is supported by the trade-off curves shown in Figures 8-11.

The overall achievements are summarised as follows:

- Integrating inerter-based devices to the design of novel mechatronic suspension systems for enhancing a bogied railway vehicle vertical performance, simplifies the design problem for low to intermediate vertical ride quality improvements (e.g. up to 30\%), by enabling suspension deflection and active force reduction.

- For further achievements over 30\% of improvement, i.e. with 'too soft' suspensions, introducing inerters does not result much beneficial to simplify the control design trade-offs.

- By integrating inerter-based suspensions with the active control strategy 'local HPF skyhook damping with adaptive stiffness', it could be obtained up to $50 \%$ in force reduction (w.r.t. $5.65[\mathrm{kN}]$ ) required for the active control strategy implemented without inerters) to achieve $30 \%$ of ride quality enhancement.

- The suspensions' maximum deflection remain inside the common bound of $3.5[\mathrm{~cm}]$ in the achievement of up to $54 \%$ of ride quality improvement for the studied control strategies with and without inerter-based suspensions. Again, 'local HPF skyhook damping with adaptive stiffness' showed the best results, followed by modal HPF skyhook damping with up to $41 \%-44 \%$ of improvement without and with inerters, respectively.

- The actuators' maximum force remain inside the common bound of $10[\mathrm{kN}]$ in the achievement of up to $54 \%$ of ride quality improvement for the studied control strategies with and without inerter-based suspensions. For this, also 'local skyhook damping with adaptive stiffness' showed the best results, followed by modal HPF skyhook damping with up to $43 \%-46 \%$ of improvement without and with inerters, respectively.

- Optimisation results related to the inerter-based configuration S1 showed that a conventional mechanical inerter estimated friction $\left(c_{b 1}=1000\left[\mathrm{Nsm}^{-1}\right]\right)$ is lower than the optimal damping value required for a $30 \%$ of ride quality improvement, hence, a damper in series is required for this configuration (see Table 7).

- Even the level of simplification of a planar model such as the side-view model we used here, the qualitative results on the potential of the inerter for the design of mechatronic suspensions were replicated - even without optimisation - in a more complex 3D model of a similar vehicle. 
The simplicity of the vertical ride quality problem, as compared to other more complex issues arising in the dynamics of a railway vehicle, enabled a better understanding of the potential of inerter-based suspension configurations. Future work will include practical aspects of passive inerters and actuators, as well as more accurate models of the vehicle to take account of engineering realities such as nonlinearities, flexibilities, etc. Further research will consider more demanding railway dynamic problems such as lateral stability and the inherent trade-off with the requirements of quasi-static curving as a more complex application of the novel mechatronic suspensions.

\section{Acknowledgements}

This work was supported by Universidad de Los Andes, Venezuela and via a departmental scholarship from the School of Electronics, Electrical and Systems Engineering, Loughborough University, UK. We thank SIMPACK UK for the support in providing a free limited license of SIMPACK Rail module. We are also thankful for the helpful discussions with Professor Malcolm Smith and Dr. Jason Jiang Zheng on the inerter applications and technology.

\section{References}

[1] R.M. Goodall and T.X. Mei, 2006, Active Suspensions. in Handbook of railway vehicle dynamics CRC Press, United States of America, p. 327.

[2] M.J. Smith, K.M. Grigoriadis, and R.E. Skelton, The Optimal Mix of Passive and Active Control in Structures, in Proceedings of the American Control Conference 1991, 1991, pp. 1459-1464.

[3] G. Corriga, S. Sanna, and G. Usai, An optimal tandem active-passive suspension system for road vehicles with minimum power consumption, Industrial Electronics, IEEE Transactions on 38 (1991), pp. 210-216.

[4] A. Giua, C. Seatzu, and G. Usai, A mixed suspension system for a half-car vehicle model, Dyn.Control 10 (2000), pp. 375-397.

[5] I. Pratt, Active suspension applied to railway trains, Loughborough University, Loughborough, United Kingdom, 1996.

[6] A. Orvnäs, On Active Secondary Suspension in Rail Vehicles to Improve Ride comfort, KTH Engineering Sciences, Stockholm, Sweden, 2011.

[7] H. Md Yusof, Technologies and control for active railway suspension actuators, Loughborough University, Loughborough, United Kingdom, 2013.

[8] F.C. Wang and H.A. Chan, Mechatronic suspension system and method for shock absorbing thereof; U.S. Patent US 2010/0148463 A1 (2010).

[9] —- Mechatronic Suspension Design and its Applications to Vehicle Suspension Control, Proceedings of the 47th IEEE Conference on Decision and Control (2008).

[10] F.C. Wang and H. Chanan , Network Optimization and Synthesis using a Combined Mechanical and Electrical System: Application to Vehicle Suspension Control, in Proceedings of the 19th International Symposium on Mathematical Theory of Networks and Systems, Budapest, Hungary, 2010.

[11] F.C. Wang and H.A. Chan, Network Optimization and Synthesis using a Combined Mechanical and Electrical System: Application to Vehicle Suspension, in Proceedings of the 19th International Symposium on Mathematical Theory of Networks and Systems MTNS 2010, Budapest, Hungary, 2010.

[12] M.C. Smith, Synthesis of mechanical networks: The inerter, IEEE Transactions on Automatic Control 47 (2002), pp. 1648-1662.

[13] S. Evangelou, D.J.N. Limebeer, R.S. Sharp, and M.C. Smith, Mechanical steering compensators for high-performance motorcycles, Journal of Applied Mechanics- Transactions of the ASME 74 (2007), pp. 332-346.

[14] S. Evangelou, D.J.N. Limebeer, R.S. Sharp, and M.C. Smith, 2006, Vol. 329, An H-inf Loop-Shaping Approach to Steering Control for High-Performance Motorcycles. in Control of Uncertain Systems (LNCIS) Springer-Verlag, Germany, p. 257.

[15] M.C. Smith, Force-controlling mechanical device; U.S. Patent US 7316303 B2 (2008).

[16] B. Gartner and M. Smith, Damping and inertial hydraulic device; PCT W0 2011/095787 A1 (2011).

[17] F.C. Wang, M.S. Hsu, W.J. Su, and T.C. Lin, Screw type inerter mechanism; U.S. Patent US 2009/0108510 A1 (2009).

[18] M.C. Smith, N.E. Houghton, P.J.G. Long, and R.A. Glover, Force-controlling hydraulic device; U.S. Patent US 2012/0199428 A1 (2012).

[19] R. Tuluie, Fluid Inerter; PCT WO 2011/089373 A1 (2011).

[20] M.Z.Q. Chen, C. Papageorgiou, F. Scheibe, F.C. Wang, and M.C. Smith, The missing mechanical circuit element, Circuits and Systems Magazine, IEEE 9; 9 (2009), pp. 10-26. 
[21] J.Z. Jiang, A.Z. Matamoros-Sanchez, R.M. Goodall, and M.C. Smith, Passive suspensions incorporating inerters for railway vehicles, Vehicle System Dynamics 50 (2012), pp. 263-276.

[22] F.C. Wang, The performance improvements of train suspension systems with inerters, Proceedings of the 45th IEEE Conference on Decision and Control 1 (2006), pp. 1110-1115.

[23] F.C. Wang, M.K. Liao, B.H. Liao, W.J. Su, and H.A. Chan, The performance improvements of train suspension systems with mechanical networks employing inerters, Vehicle System Dynamics 47 (2009), pp. 805-830.

[24] F.C. Wang and M.K. Liao, The lateral stability of train suspension systems employing inerters, Vehicle System Dynamics 48 (2009), pp. 619-643.

[25] J.Z. Jiang, A.Z. Matamoros-Sanchez, R.M. Goodall, and M. Smith, 2012, Performance Benefits in Two-Axle Railway Vehicle Suspensions Employing Inerters. in Developments in Control Theory towards Glocal Control Institute of Engineering and Technology (IET).

[26] F.C. Wang, M.R. Hsieh, and H.J. Chen, A full-train with inerters: stability and performance, in Proceedings of the 22nd International Symposium on Dynamics of Vehicles on Roads and Tracks, Manchester, UK, 2011.

[27] S. Bruni, R. Goodall, T.X. Mei, and H. Tsunashima, Control and monitoring for railway vehicle dynamics, Vehicle System Dynamics 45 (2007), pp. 743-779.

[28] A.Z. Matamoros-Sanchez, The use of novel mechanical devices for enhancing the performance of railway vehicles, Loughborough University, Loughborough, United Kingdom, 2013.

[29] S. Bruni, J. Vinolas, M. Berg, O. Polach, and S. Stichel, Modelling of suspension components in a rail vehicle dynamics context, Vehicle System Dynamics 49 (2011), p. 1021.

[30] H. Li, Non-linear control approaches for active railway suspensions; M.Phil thesis, Loughborough University, 1997.

[31] E. Foo and R. Goodall, Active suspension control strategies for flexible-bodied railway vehicles, in Proceedings of Control '98. UKACC International Conference on (Conf. Publ. No. 455), Vol. 2, 1998 , pp. $1300-1305$.

[32] X. Zheng, Active vibration control of flexible bodied railway vehicles via smart structures, Loughborough University, Loughborough, United Kingdom, 2011.

[33] H. Li and R.M. Goodall, Linear and non-linear skyhook damping control laws for active railway suspensions, Control Engineering Practice 7 (1999), pp. 843-850.

[34] A.Z. Matamoros-Sanchez and R.M. Goodall, The optimisation problem in the enhancement of railway vehicles performance using novel suspension systems, in Proceedings of the XI International Congress on Numerical Methods in Engineering and Applied Sciences, Venezuela, 2012.

[35] International Organization for Standardization, ISO 2631-1; 1997.

[36] V.K. Garg and R.V. Dukkipati Dynamics of Railway Vehicle Systems, Accademic Press, United Kingdom, 1984

[37] CEN, European prestandard ENV 12299; 1999.

[38] N.J. Mansfield, Literature Review on Low Frequency Vibration Comfort, , 2006 Asia Link Program.

[39] R. Narayanamoorthy, V.H. Saran, V.K. Goel, S.P. Harsha, S. Khan, and M. Berg, Determination of Activity Comfort in Swedish Passenger Trains, in Proceedings of the 8th World Congress on Railway Research, Seoul, Korea COEX, 2008.

[40] M.K. Bhiwapurkar, V.H. Saran, S.P. Harsha, V.K. Goel, and M. Berg, Effect of Magnitudes and Directions (Mono-Axis and Multi-Axis) of Whole Body-Vibration Exposures and Subjects Postures on the Sketching Performance, Proceedings of the Institution of Mechanical Engineers, Part F: Journal of Rail and Rapid Transit 225 (2011), pp. 71-83.

[41] D. Karnopp, 1973, Vol. 1, Active and passive isolation of random vibration. in Isolation of Mechanical Vibration Impact and Noise ASME Monograph, American Society of Mechanical Engineers, New York, p. 64.

[42] MathWorks, Optimization Toolbox. Matlab R2012b., Matlab Users Guide (2012)

[43] P. Dorato, C. Abdallah, and V. Cerone Linear-Quadratic Control: An Introduction, Prentice Hall, USA, 1995

[44] G.F. Franklin, J.D. Powell, and A. Emami-Naeini Feedback Control of Dynamic Systems, 4th edition Prentice Hall, Upper Saddle River, NJ, 2002.

[45] S. Iwnicki, The Manchester Benchmarks for rail simulators - an introduction, Vehicle System Dynamics 29 (1998), pp. 717-722.

[46] — Manchester Benchmarks for Rail Vehicle Simulation, Vehicle System Dynamics 30 (1998), pp. 295-313.

\section{Nomenclature}

$\beta_{v} \quad$ Vehicle body pitching mode [rad]

$\beta_{b 1,2} \quad$ Leading and trailing bogie pitching mode [rad]

$\dot{S}_{t}^{\dot{\delta}_{z}}\left(\omega_{t}\right)$ p.s.d. of the track elevation rate $\left[(\mathrm{m} / \mathrm{s})(\mathrm{rad} / \mathrm{s})^{-1}\right]$

$\kappa \quad$ A design parameter in HPF skyhook damping with adaptive stiffness control strategy

$\mathbf{A}, \mathbf{B}_{u}, \mathbf{C}_{m}, \mathbf{D}_{u}, \mathbf{C}_{\chi}, \mathbf{D}_{\chi}, \mathbf{K}_{u}, \mathbf{K}_{e}, \mathbf{Q}, \mathbf{R}, \mathbf{V}, \mathbf{W}, \eta$ Scalar and matrix parameters in the linear-quadratic output regulator design

$\Omega_{z} \quad$ Vertical roughness coefficient $[\mathrm{m}]$ 
F\&S0, F\&S1, F\&S2 Labels for hybrid suspensions

S0, S1, S2 Labels for passive suspensions, being S0 the conventional airspring and S1-S2 inerter-based structures

$\sigma \quad$ Variance symbol

$\underline{x^{\prime}}(t), \underline{\tilde{x}^{\prime}}(t)$ State vector and estimated state vector in the linear-quadratic output regulator

$\underline{y_{m}(t)}$ Measured output for the linear-quadratic output regulator

$\underline{\underline{y_{\ddot{z} v}}} \quad$ Vector of vehicle r.m.s. accelerations $\left[\mathrm{ms}^{-2}\right]$

$\overline{c_{s k y}}, K_{l}, K_{b}, K_{\rho}$ Control gains in sky-hook damping configurations

$f_{c} \quad$ Filtering corner frequency for the sky-hook damping configurations [Hz]

$F_{a 1,2} \quad$ Front and rear airspring forces $[\mathrm{N}]$

$F_{c 1,2} \quad$ Front and rear suspension active forces [N]

$F_{p 1-4}$ Primary suspension forces connecting leading and trailing wheelsets to the front and rear bogies $[\mathrm{N}]$

$F_{p n, 1-2}$ Front and rear suspension passive network forces $[\mathrm{N}]$

$F_{u 1,2}$ Front and rear mechatronic forces [N]

$f_{w z}(t)$ Deterministic profile function $[\mathrm{m}]$

$G_{\mathrm{HPF}}(s), G_{\mathrm{LPF}}(s)$ Transfer functions of high-pass and low-pass filters for sky-hook damping configurations

$J_{1} \quad$ Vector of ride quality penalisation indices [\%g]

$J_{1}^{\text {sup }} \quad$ Least ride quality penalisation index $[\% \mathrm{~g}]$

$J_{2} \quad$ Suspension deflection index vector $[\mathrm{cm}]$

$J_{3} \quad$ Active force index vector $[\mathrm{N}]$

$J_{L Q R}$ Performance measure of the linear-quadratic output regulator

$x_{i D 1,2}(t), x_{p f 1,2}(t), \chi(t), \zeta(t), \theta(t)$ Variables in the linear-quadratic output regulator design

$z_{v} \quad$ Vehicle body vertical bouncing mode $[\mathrm{m}]$

$z_{b 1,2} \quad$ Leading and trailing bogie bouncing mode $[\mathrm{m}]$

$z_{w 1-4}$ Vertical track profile entering through the wheelsets of the leading and trailing bogies $[\mathrm{m}]$

$\mathrm{Y}_{a}(s)$ Airspring (secondary suspension) admittance function.

$\mathrm{Y}_{p}(s)$ Primary suspension admittance function. 